
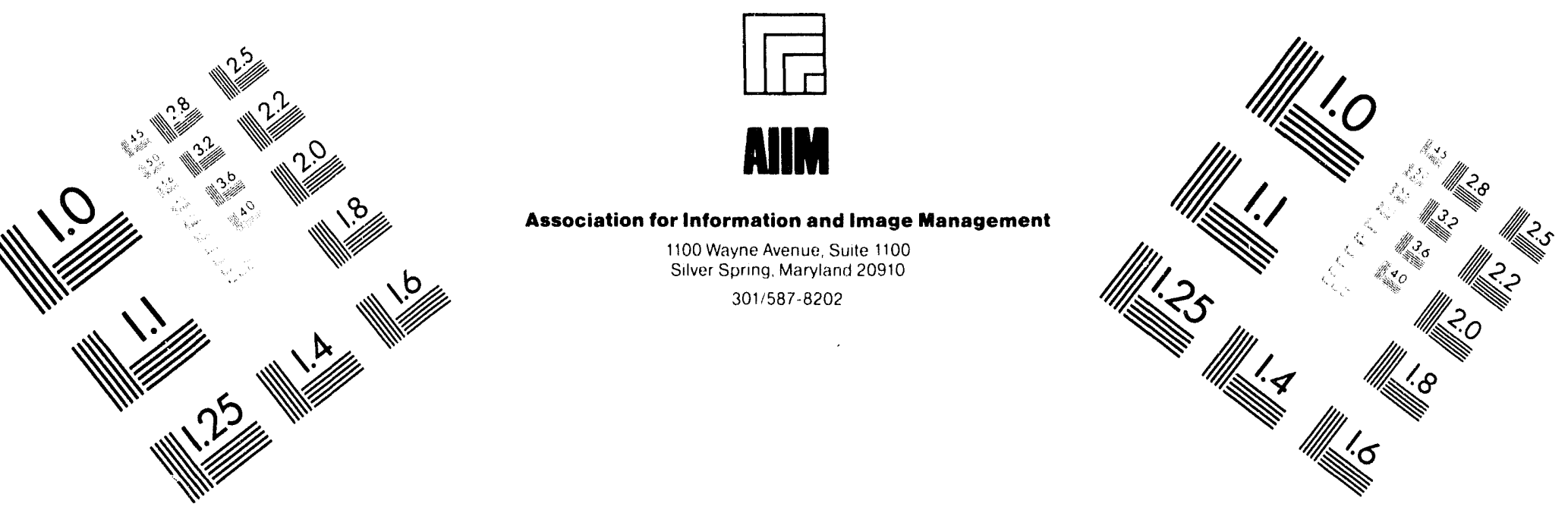

\title{
Centimeter
}

${ }_{1}$

Inches
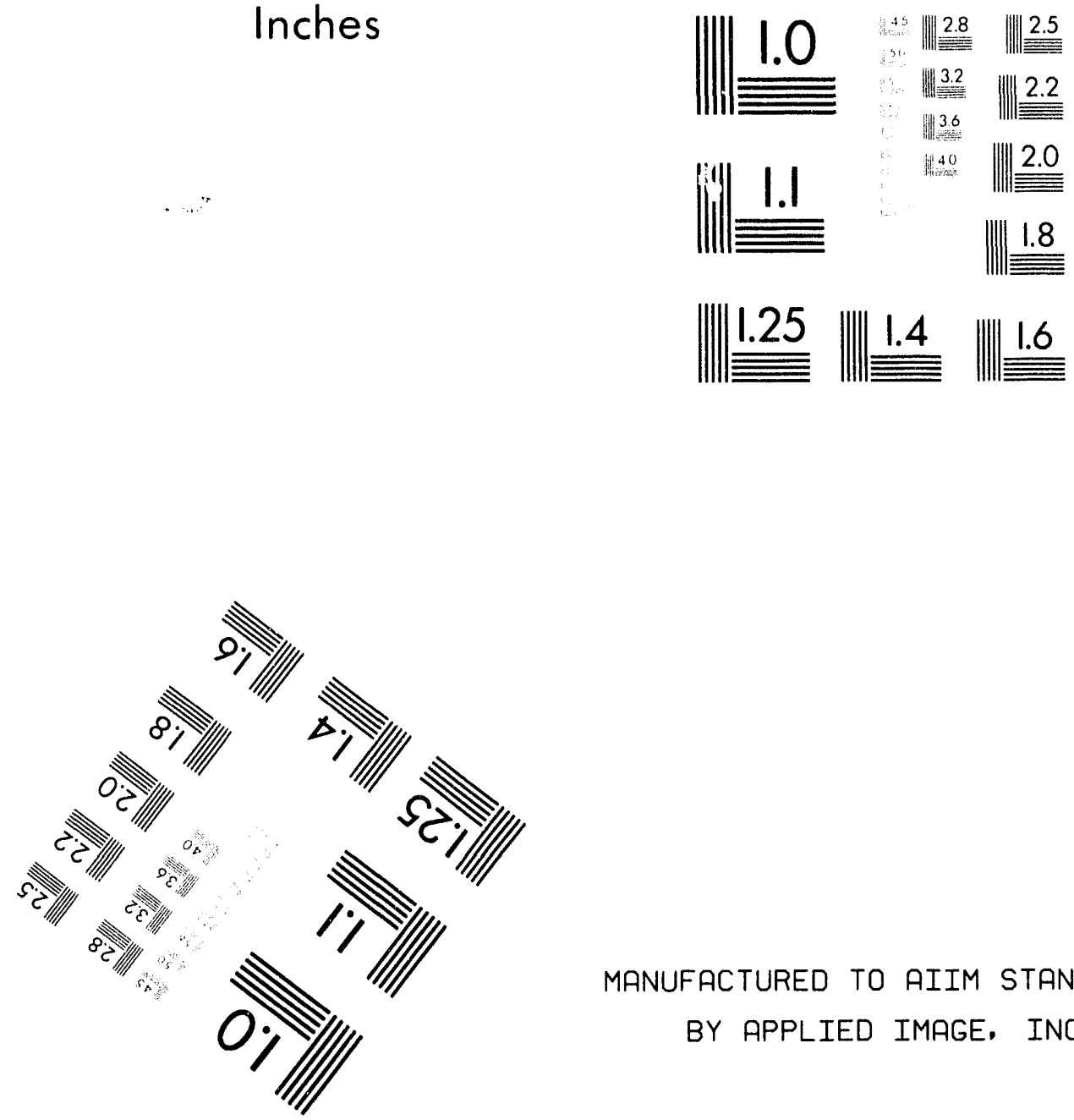

MANUFACTURED TO AIIM STANDARDS

BY APPLIED IMAGE. INC.

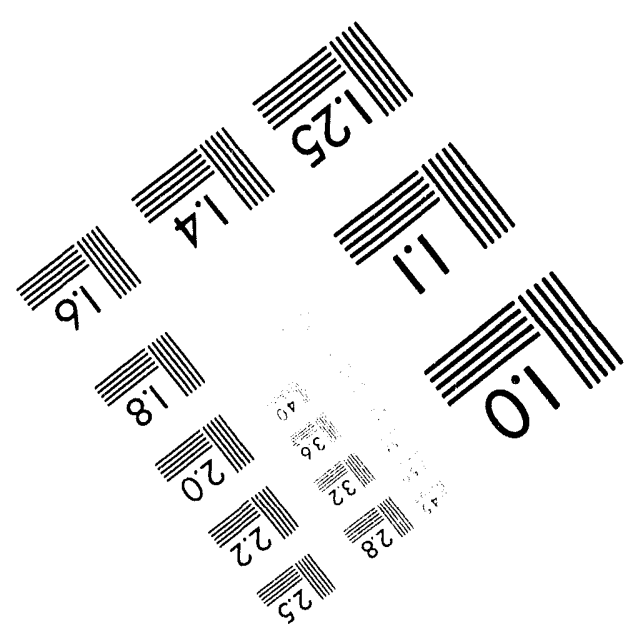



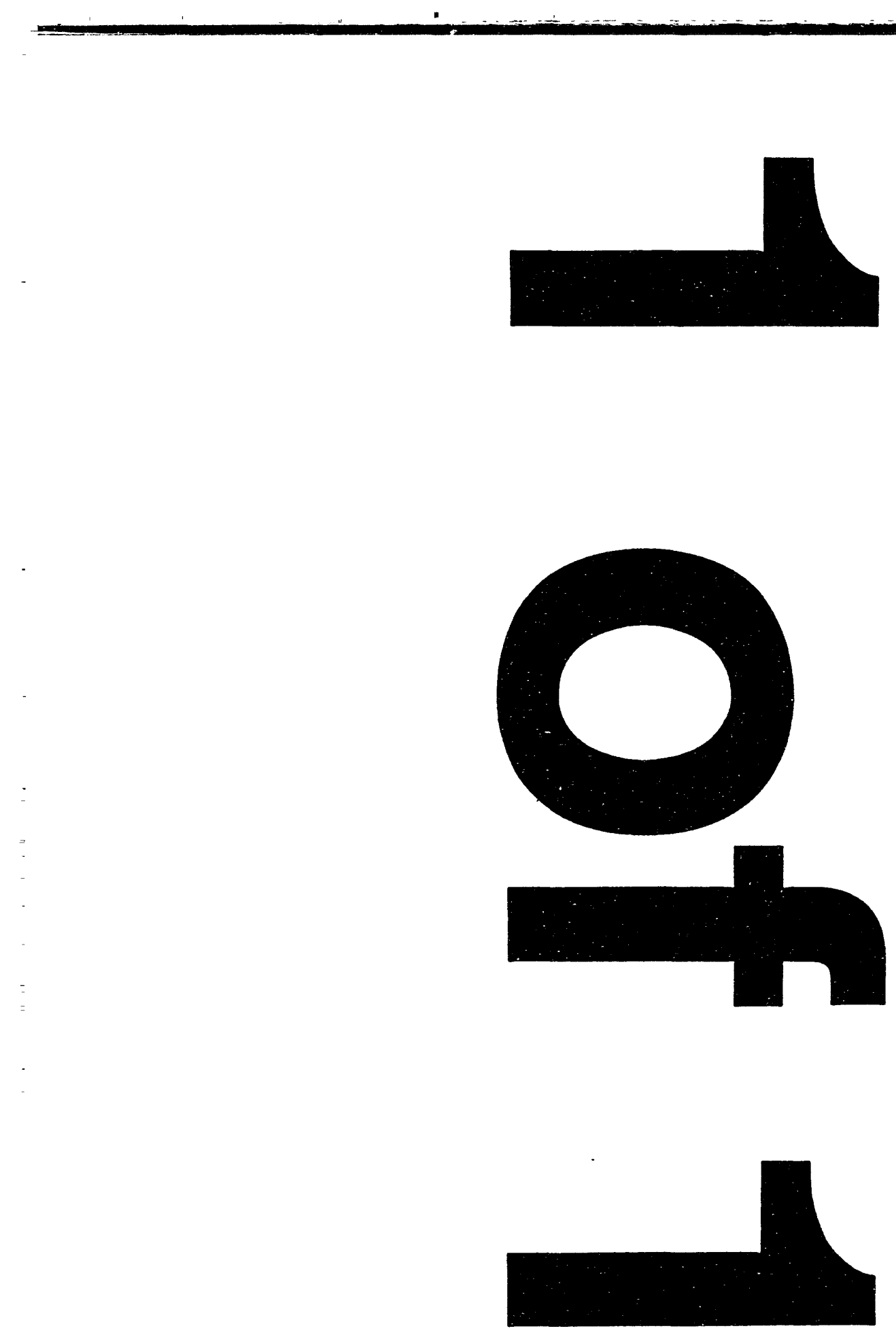


\section{Technical Evaluation of Software for Gamma-Ray Logging System}

A report for Westinghouse Hanford Company, Tank Waste Surveillance Systems

D. C. Stromswold

May 1994

Prepared for the U.S. Department of Energy under Contract DE-AC06-76RL0 1830

Pacific Northwest Laboratory

Richland, Washington 99352 


\section{Summary}

This report contains results of a technical review of software, identified as LGCALC, that processes data collected by a high-resolution gamma-ray borehole logging system. The software presently operates within Westinghouse Hanford Company, Department of Geosciences, to process data collected by the Radionuclide Logging System. The software has been reviewed for its suitability for processing data to be collected by new high-resolution gamma-ray logging trucks scheduled to begin operational tests within Westinghouse Tank Waste Remediation Systems during 1994.

Examination of the program code and hands-on operational tests have shown that this software is suitable for its intended use of processing high-resolution gamma-ray data obtained from borehole logging. Most of the code requires no changes, but in a few limited cases, suggestions have been made to correct errors or improve operation. Section 4 describes these changes.

The technical review has confirmed the appropriateness, correctness, completeness, and coding accuracy of algorithms used to process spectral gamma-ray data, leading to a calculation of subsurface radionuclide contaminants. The reviewed algorithms include peak identification, peak area calculation, corrections for borehole effects (e.g., casing and water), and calculation of radionuclide concentrations. The review also covered the adequacy of comment statements within the Fortran code to guide a person unfamiliar with this specific code, but knowledgeable in Fortran programming, gamma-ray spectrum analysis, and borehole logging data.

Running the program with test data from calibration models has confirmed that the program operates correctly. Comparisons with "hand calculations" have shown the correctness of the output from the program, based on known input data. Section 3 describes these tests.

The recommended action is to make the "near term" programming changes suggested in Section 4.1 and then use the LGCALC analysis program with the new high-resolution logging systems once they have been properly calibrated. 


\section{Contents}

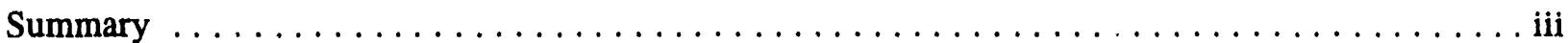

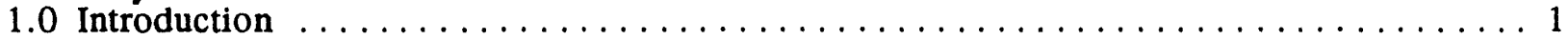

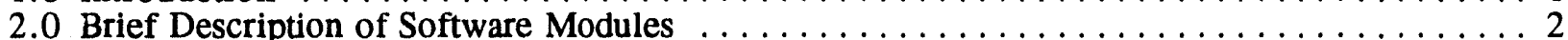

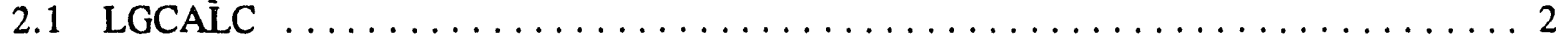

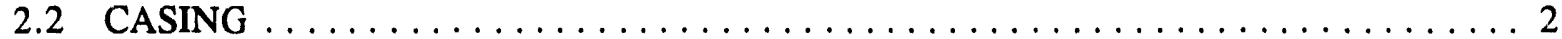

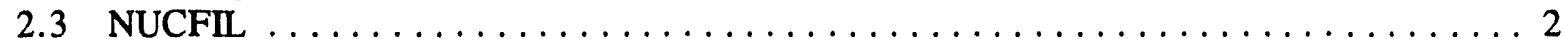

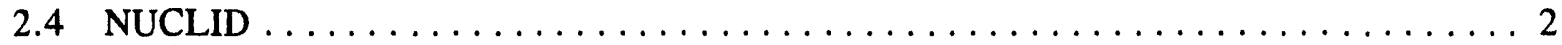

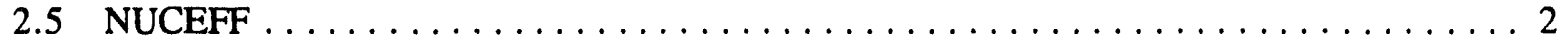

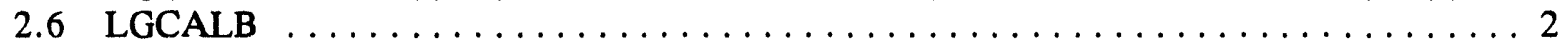

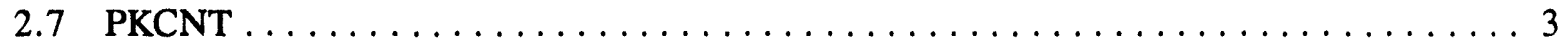

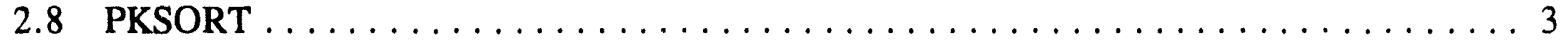

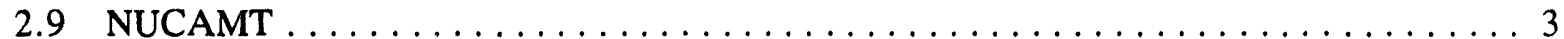

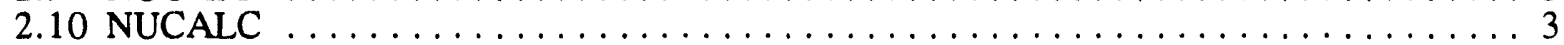

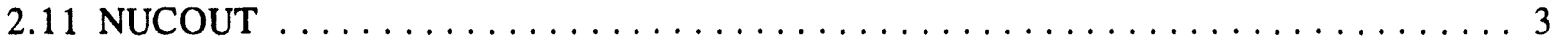

3.0 Operational Tests Results $\ldots \ldots \ldots \ldots \ldots \ldots \ldots \ldots \ldots \ldots \ldots \ldots \ldots \ldots \ldots \ldots$

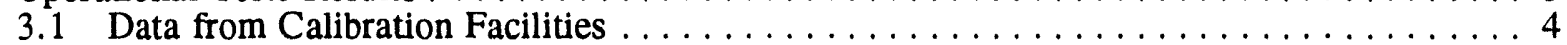

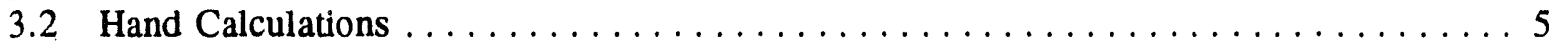

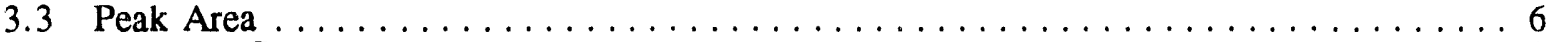

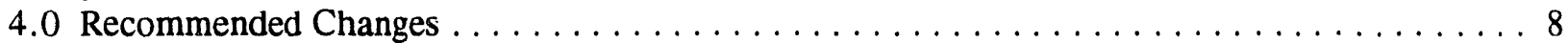

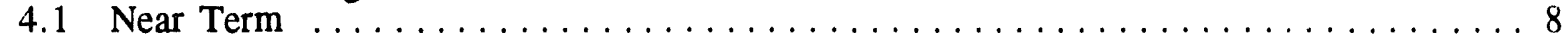

4.1.1 Statistical Uncertainties and Weighted Averaging $\ldots \ldots \ldots \ldots \ldots \ldots \ldots \ldots$

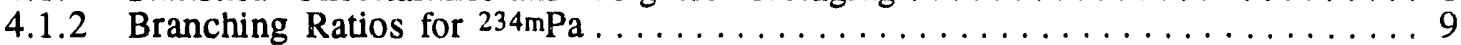

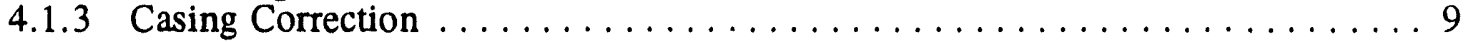

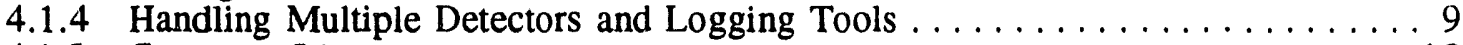

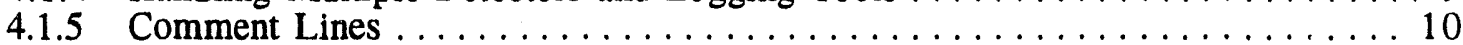

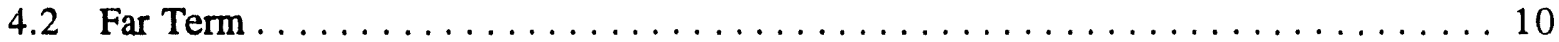

4.2.1 Peak Identification and Area Calculation $\ldots \ldots \ldots \ldots \ldots \ldots \ldots \ldots \ldots \ldots$

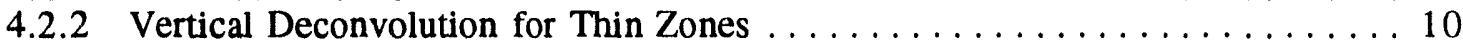

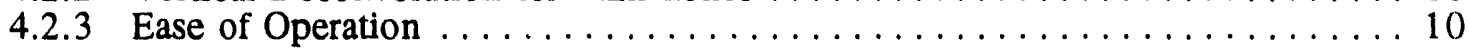

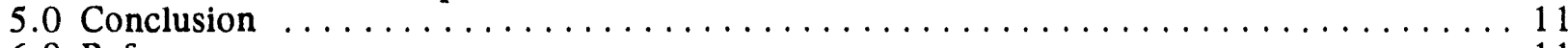

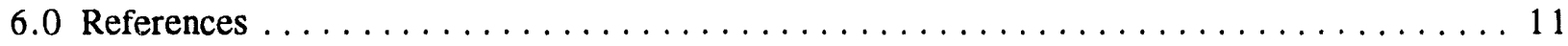

Appendix A. Program Questions Addressed During Evaluation and Recommended Code Changes .. 


\section{Tables}

3.1.1 Concentration Calculation Test using Hanford Spectral Gamma-ray Models . . . . . 4

3.1.2 Casing Tests using Grand Junction KW Model $\ldots \ldots \ldots \ldots \ldots \ldots \ldots \ldots \ldots \ldots$

3.1.3 Water-Filled Hole Tests using Grand Junction $\mathrm{KW}$ Model $\ldots \ldots \ldots \ldots \ldots \ldots \ldots \ldots .5$

3.2.1 Detector Efficiency and Casing Correction $\ldots \ldots \ldots \ldots \ldots \ldots \ldots \ldots \ldots$

3.3.1 Peak Area Calculations using Field Data $-60 \mathrm{Co} \ldots \ldots \ldots \ldots \ldots \ldots \ldots \ldots \ldots$

3.3.2 Peak Area Calculations using Hanford Calibration Model Data (Mixed Zone) . . . . . . 8 


\subsection{Introduction}

An alternatives analysis report (Engelman et al. 1993) identified Westinghouse Hanford Company's (WHC's) LGCALC software, written by Randall K. Price, as an appropriate choice, pending further technical evaluation, to analyze data collected by new logging trucks at tank farms. That software presently processes data collected by the Radionuclide Logging System (RLS). The RLS, which was the design base for the tank farms logging systems, has operated at Hanford for over five years, logging more than 200 boreholes. That system has a borehole probe containing a germanium detector to detect ganma-rays emitted by radionuclides in the subsurface. A winch on the back of a special truck moves the probe in the boreholes for data collection. A multichannel analyzer and a computer in the vehicle receive data from the probe and store the spectral data along with the depth of the probe for future analysis. The stored data are subsequently transferred from the RLS to a fixed facility for analysis where the LGCALC software performs the following functions:

1. Reads spectral data into system

2. Analyzes spectrum

a. locates peaks in spectrum

b. determines peak centroid

c. determines background-subtracted peak areas (counts/s in peaks), including statistical uncertainty

3. Determines energy calibration (channel number to energy relationship)

4. Identifies radionuclides based on gamma-ray energy

5. Adjusts peak areas based on known

a. attenuation of gamma rays by steel casing in hole

b. effects of liquid-filled boreholes of various diameters

6. Calculates radionuclide concentrations using

a. peak areas

b. gamma-ray emission properties (e.g., branching ratios)

7. For nuclides with multiple peaks, determines "best" concentration based on statistical uncertainties

8. Sums all channels to give gross value for entire energy spectrum and divides by counting time

9. Generates report (separate software from analysis program)

a. graphical display (borehole log) using commercial program "Sigma Plot"

b. analyst's findings and comments

Special features of the software include

1. Processing data with low counting rates (i.e., statistical data where peaks are difficult to identify)

2. Automatic energy re-calibration in case of gain changes

3. Special calibration for borehole geometry

4. Application of "correction factors" for borehole conditions (diameter, fluid, and casing) different from those during probe calibration

5. Storage and retrieval of data in depth-ordered files

6. Presentation of results as borehole logs.

Before accepting this software to analyze data from the new logging trucks, a formal review of its adequacy and correctness was needed. That review included a technical evaluation of the software, which has now been completed and is described in this report from Pacific Northwest Laboratory. ${ }^{a}$

a Pacific Northwest Laboratory is operated for the U. S. Department of Energy by Battelle Memorial Institute under Contract DE-AC06-76RLO 1830. 


\subsection{Brief Description of Software Modules}

The software that processes the logging data is written in modular form with subroutines being called by a main program. A brief description of the functions of these modules follows.

\subsection{LGCALC}

This is the main program that calls the subroutines listed below during the process of calculating radionuclide concentrations from logging data. It also brings logging data into the program for processing, allows the operator to enter well information (such as depth and casing thickness), keeps track of casing thickness and water-filled hole diameter at each depth, and closes files when the program is finished. Processing proceeds by bringing in a spectrum corresponding to a given depth in the hole, analyzing that spectrum (by locating peaks, determining peak areas, converting to concentrations, and making correction for casing, etc), recording the results, and then bringing in the next depth's spectrum for processing.

\subsection{CASING}

This subroutine displays information on the analyst's screen related to the steel casing in the borehole. It sums casing thickness in cases of multiple strings of casing in the hole. It also determines depths within the well at which the casing thickness changes or the borehole changes from air-filled to water-filled. It identifies depth intervals in the hole for which casing thickness and waterfilled borehole diameter are constant. These depth intervals are used in later calculations where corrections for casing and hole diameter are made. Results of this borehole partitioning are displayed on the operator's screen for checking.

\subsection{NUCFIL}

This subroutine opens files for output concentrations and writes heading records.

\subsection{NUCLID}

This subroutine reads a file containing information on standard gamma rays (their energy and number of gamma rays emitted per decay) to prepare for spectrum analysis. It builds a table of this information and checks for possible overlap between peaks in the table. A warning is written if overlap is found.

\subsection{NUCEFF}

This subroutine contains stored calibration and correction information obtained from prior calibration of the logging tool. Based on these calibration data, the subroutine determines a detector efficiency factor for each gamma-ray peak present in the logging data. It also determines correction factors for the presence of casing, water, and surrounding lead shield for each gamma-ray. It writes these factors, along with their statistical uncertainties, into a common storage location for later use.

\subsection{LGCALB}

This subroutine updates the channel number-to-energy calibration that was initially established by the log analyst at the start of the session. Gain drifts during the logging process can shift the channel in which a given energy gamma ray appears, necessitating recalibration of the energy scale. This subroutine does that by looking for prominent peaks near known energies (e.g., $662 \mathrm{keV}$ peak from ${ }^{137} \mathrm{Cs}$, or $1461 \mathrm{keV}$ from ${ }^{40} \mathrm{~K}$ ). 


\subsection{PKCNT}

This subroutine searches for peaks in the gamma-ray spectrum. Peaks are identified by stepping through the spectrum, comparing the counts in a given channel with a threshold value. The threshold is determined from average counts in preceding channels and their statistical uncertainty. The ending channel for the peak is established where the counts fall below the same threshold. For peak locations that contain very few counts, the peak limit is established where two zero-count channels are encountered above or below the peak. Once a peak is found, the counts in the peak are obtained by summing counts in the individual channels defining the peak. Background subtraction is based on the average counts in channels before and after the peak. Dividing by the counting (live) time gives the peak count rate. The subroutine also calculates the statistical uncertainty in the count rate. The results are saved for later use in calculating concentrations.

\subsection{PKSORT}

This subroutine identifies the peaks found in PKCNT with their source radionuclide, based on the energy of the gamma-ray peak. Some radionuclides have multiple gamma rays (e.g., 60 Co with 1173 and $1333 \mathrm{keV}$ ), which are stored together with their common radionuclide. Peaks that the routine cannot identify are stored separately.

\subsection{NUCAMT}

This subroutine determines nuclide concentration using a call to the subroutine NUCALC for each gamma-ray peak found in the spectrum. For nuclides with multiple peaks, NUCAMT calculates the best result to present based on statistical uncertainty for the multiple peaks.

\subsection{NUCALC}

This subroutine calculates nuclide concentration for each gamma-ray peak based on the net peak count rate, detector efficiency, and correction factors. Correction factors account for attenuation of the gamma-ray count rate by the steel casing, water in the borehole, and lead shield (if any) around the logging tool. Statistical uncertainties in the concentration are also calculated.

\subsection{NUCOUT}

This subroutine moves calculated concentrations and their statistical uncertainties to the output record.

\subsection{Operational Test Results}

Processing data collected by the logging system in locations where radionuclide concentrations are known provides an excellent method for checking the correctness of the analysis software. The requirement for known concentrations generally excludes all field data from actual boreholes because the concentrations there are not independently known. Even when core samples are available from holes, a valid comparison with logging data is often difficult because the volume of investigation around the borehole is much larger for logging than it is for the core samples (Hearst et al. 1993). Consequently, radionuclides distributed non-uniformly in the subsurface make meaningful comparisons between log data and core data almost impossible. However, processing data collected in calibration models, such as those located at Hanford and Grand Junction, Colorado, provides a good alternative to field data to check the analysis program. 


\subsection{Data from Calibration Facilities}

Calibration coefficients for the logging system that are incorporated in the software were obtained using data collected in models at Grand Junction, Colorado, the primary site for DOE borehole models (Steele and George 1986). The calibration coefficients in the analysis program during these operational tests are based on data collected in Grand Junction mainly in 1991 and 1992. A limited number of spectral gamma-ray calibration models also exists at Hanford. Running the logging tool in the Hanford models provides a check of the tool's calibration and the software that calculates concentrations. Table 3.1.1 compares the tool's measured concentrations to the assigned concentrations for the Hanford models. These comparisons are for uricased, air-filled boreholes of diameter 4.5 inches. The general agreement between the assigned and measured values supports the correct operation of the software.

Some differences exist between the assigned and measured concentrations in Table 3.1.1, however. For example, the $\mathrm{K}$ concentration in the Th zone is measured as $14.8 \mathrm{pCi} / \mathrm{g}$ by the logging tool, whereas the assigned value is $10.6 \mathrm{pCi} / \mathrm{g}$. In this case, the measured concentration is high due to an interference with the $\mathrm{K}$ peak that comes from a decay product (228 Ac with $1459-\mathrm{keV}$ gamma ray) of Th. Where Th concentration is high, such as in these calibration models, a correction needs to be made in the measured $\mathrm{K}$ concentration. This correction would not be necessary for field data where Th concentrations are typically very low. When the correction is made, the resulting value $\mathrm{K}$ concentration is $9.8 \mathrm{pCi} / \mathrm{g}$, which is in better agreement with the assigned value of $10.6 \mathrm{pCi} / \mathrm{g}$. Similarly, the "mixed" zone's measured $\mathrm{K}$ is high due to the Th interference. When the correction is made, the measured value becomes $43.4 \mathrm{pCi} / \mathrm{g}$, in comparison with the assigned value of $41.8 \mathrm{pCi} / \mathrm{g}$. Finally, the Th concentrations in the Th and mixed zones are low, based on the $911-\mathrm{keV}$ gamma-ray peak, which the analysis program used because it provided the lowest percent uncertainty in the calculated concentration. The $2615-\mathrm{keV}$ gamma ray from Th, which had almost as small an uncertainty, provided Th concentrations of $56.7 \mathrm{pCi} / \mathrm{g}$ and $38.4 \mathrm{pCi} / \mathrm{g}$ for these two zones, in closer agreement with the assigned values. A weighted average concentration based on both the 911 - and $2615-\mathrm{keV}$ peaks would have been beneficial in this case. See Section 4.1.1 for recommended changes in the analysis program regarding weighted averaging of concentrations for radionuclides that emit multiple gamma rays. For the U concentrations, the program used either the 1120- or the $1764-\mathrm{keV}$ gamma ray, whichever gave the lowest percent uncertainty. A weighted average for $U$ would have had little effect on the calculated concentration in these test cases.

Table 3.1.1 Concentration Calculation Tests using Hanford Spectral Gamma-ray Models

\begin{tabular}{|c|c|c|c|c|c|c|}
\hline \multirow[t]{2}{*}{ Zone } & \multicolumn{2}{|c|}{$\underset{(\mathrm{pCi} / \mathrm{g})}{\mathrm{K}}$} & \multicolumn{2}{|c|}{$\underset{(p C i / g)}{U}$} & \multicolumn{2}{|c|}{$\underset{(\mathrm{pCi} / \mathrm{g})}{\mathrm{Th}}$} \\
\hline & Assigned & Meas. & Assigned & Meas. & Assigned & Meas \\
\hline $\begin{array}{l}\text { Th } \\
\text { K } \\
\text { U } \\
\text { Mix }\end{array}$ & $\begin{array}{l}10.6 \\
53.5 \\
10.7 \\
41.8\end{array}$ & $\begin{array}{l}14.8 \\
55.0 \\
10.2 \\
46.7\end{array}$ & $\begin{array}{r}10.0 \\
1.2 \\
191 \\
126\end{array}$ & $\begin{array}{r}9.9 \\
1.2 \\
191 \\
127\end{array}$ & $\begin{array}{r}58.1 \\
0.1 \\
0.7 \\
39.1\end{array}$ & $\begin{array}{r}51.1 \\
0.1 \\
0.5 \\
34.2\end{array}$ \\
\hline
\end{tabular}

Steel casing in a borehole attenuates the gamma rays passing from the formation to the detector. Corrections for this attenuation are applied by a multiplicative "casing correction factor" determined experimentally during calibration of the logging system. The correction factor is a function of casing thickness and gamma-ray energy. The Hanford spectral gamma-ray models do not have hole diameters large enough to insert casings to check the software's analysis for casing corrections. The comparison data in Table 3.1.2 came from the Grand Junction "KW" model's 12inch-diameter hole. This is the model where the casing corrections were originally obtained. The agreement between assigned and measured values shows consistency of operation for this model. 
The measured $\mathrm{K}$ concentration shown in the table is higher than the assigned concentration due to interference by a $1459.2-\mathrm{keV}$ gamma ray from Th. When this interference is removed, the measured concentration becomes $38.4 \mathrm{pCi} / \mathrm{g}$ for the 0.33 " casing and $39.1 \mathrm{pCi} / \mathrm{g}$ for the $0.40^{\prime \prime}$ casing. Also shown in Table 3.1.2 are the uncorrected, measured concentrations. These are the values obtained before the casing corrections are applied. The large differences between these uncorrected values and the assigned values illustrate the importance of making the casing correction.

Table 3.1.2 Casing Tests using Grand Junction KW Model

\begin{tabular}{|c|c|c|c|c|c|c|c|c|c|}
\hline \multirow[t]{2}{*}{$\begin{array}{l}\text { Casing } \\
\text { Thickness }\end{array}$} & \multicolumn{3}{|c|}{$\underset{(p \mathrm{Ci} / \mathrm{g})}{\mathbf{K}}$} & \multicolumn{3}{|c|}{$\underset{(\mathrm{pCi} / \mathrm{g})}{\mathrm{U}}$} & \multicolumn{3}{|c|}{$\underset{(\mathrm{pCi} / \mathrm{g})}{\mathrm{Th}}$} \\
\hline & Assigned & 1 Meas. & Uncorr. & Assigned & Meas. & Uncorr. & Assigned & Meas. & Uncorr. \\
\hline $\begin{array}{l}0.33^{\prime \prime} \\
0.40^{\prime \prime}\end{array}$ & $\begin{array}{l}38.4 \\
38.4\end{array}$ & $\begin{array}{l}41.0 \\
41.7\end{array}$ & $\begin{array}{l}26.8 \\
25.2\end{array}$ & $\begin{array}{l}121 \\
121\end{array}$ & $\begin{array}{l}121 \\
123\end{array}$ & $\begin{array}{l}81.8 \\
77.8\end{array}$ & $\begin{array}{l}26.7 \\
26.7\end{array}$ & $\begin{array}{l}26.8 \\
27.1\end{array}$ & $\begin{array}{l}13.8 \\
12.4\end{array}$ \\
\hline
\end{tabular}

The various hole diameters in the Grand Junction $\mathrm{KW}$ model also provide a means for checking the accuracy of the corrections for the presence of water in boreholes. The Hanford models do not have large enough hole diameters to be useful for this. The KW model provided the original calibration data for the water correction. Using it to check the correction serves as a consistency test. Table 3.1.3 shows the results of the measured concentrations (with the calibrated water correction applied) for 7-inch and 12-inch diameter holes with the tool centralized in the holes, which is the normal configuration for logging. The measured and assigned concentrations are in reasonably good agreement. As with previous results, the measured $\mathrm{K}$ concentrations are somewhat high due to interference from the Th in the model. The measured Th concentrations are based on the $911 \mathrm{keV}$ peak. A weighted average including additional Th peaks (583 and $2615 \mathrm{keV}$ ) would have produced measured values of about 25.5 and $25.2 \mathrm{pCi} / \mathrm{g}$ for the $7^{\prime \prime}$ and $12^{\prime \prime}$ holes, respectively, in closer agreement with the assigned value $26.7 \mathrm{pCi} / \mathrm{g}$. Most Hanford logging occurs above the water table where no water correction is needed. No correction is required for air-filled holes because the air does not significantly attenuate gamma rays for the hole diameters (up to 12 inches) at Hanford. For holes that actually do contain water, Table 3.1.3 illustrates the importance of making a water correction because the uncorrected concentrations from the logging data can be significantly low.

Table 3.1.3. Water-filled Hole Tests using Grand Junction KW Model

\begin{tabular}{|c|c|c|c|c|c|c|c|c|c|}
\hline \multirow[t]{2}{*}{$\begin{array}{l}\text { Hole } \\
\text { Diam. }\end{array}$} & \multicolumn{3}{|c|}{$\underset{(\mathrm{pCi} / \mathrm{g})}{\mathbf{K}}$} & \multicolumn{3}{|c|}{$\underset{(\mathrm{pCi} / \mathrm{g})}{\mathrm{U}}$} & \multicolumn{3}{|c|}{$\underset{(\mathrm{pCi} / \mathrm{g})}{\mathrm{Th}}$} \\
\hline & Assigned & 1 Meas. & Uncorr. & Assigned & Meas. & Uncorr. & Assigned & Meas. & Uncorr. \\
\hline $\begin{array}{l}7 " \\
12 "\end{array}$ & $\begin{array}{l}38.4 \\
38.4\end{array}$ & $\begin{array}{l}41.6 \\
42.2\end{array}$ & $\begin{array}{l}28.6 \\
18.8\end{array}$ & $\begin{array}{l}121 \\
121\end{array}$ & $\begin{array}{l}126 \\
124\end{array}$ & $\begin{array}{l}87.7 \\
57.3\end{array}$ & $\begin{array}{l}26.7 \\
26.7\end{array}$ & $\begin{array}{l}23.2 \\
23.6\end{array}$ & $\begin{array}{l}15.0 \\
14.2\end{array}$ \\
\hline
\end{tabular}

\subsection{Hand Calculations}

Calculations performed using a calculator provided spot checks of the program's performance in calculating various values used in determining concentrations from the raw gammaray data. The detector efficiency factor for converting peak area to radionuclide concentration and the multiplicative casing correction factor are two parameters checked. Table 3.2.1 shows that the values obtained by hand calculations and by the analysis program are in good agreement, except for 
the uncertainty in the casing correction. The program's algorithm for determining this uncertainty needs to be changed to calculate this uncertainty properly, as discussed in Section 4.1.1 and Appendix A. The data for Table 3.2.1 are based on a Hanford well $\log$ where the casing thickness was taken as 0.40 inches, rather than the actual 0.47 inches, because the logging system was not calibrated for casings thicker than 0.40 inches. In future calibrations, the casing corrections should be extended to approximately 1.0 -inch-thick casings to cover the range of casings present at Hanford.

Table 3.2.1. Detector Efficiency and Casing Correction

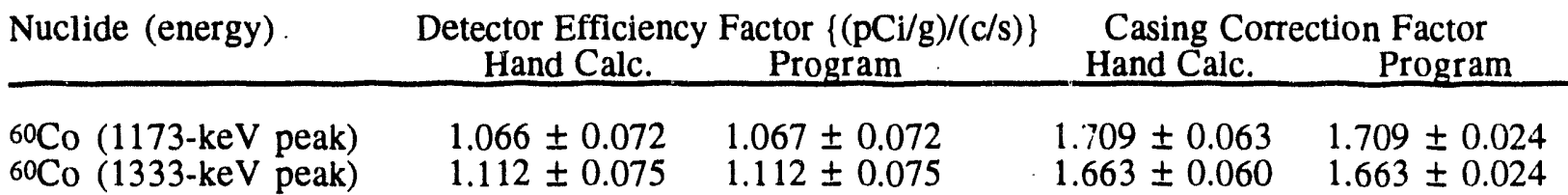

Well T50-01-06, sample depth $=55.0 \mathrm{ft}$, casing thickness $=0.40$ inches; uncertainties are 1 std. dev.

\subsection{Peak Area}

Peak area calculations and count rates were checked by hand calculations and were compared with the results from two commercial programs from Ortec (Omnigam and Gamma Vision) and RayGun, a program originally developed at Lawrence Livermore National Laboratory. This is not intended as a test of peak location and identification (although all programs found the peaks readily), but rather a check of the calculations involved in determining peak areas and their corresponding count rates. All five methods calculate count rates after selecting limits for the extent of the peaks (as opposed to fitting a predetermined functional shape to the peak) and subtracting background. The methods can differ in how they select peak limits and determine background. There is no one, "correct" method for determining peak areas and backgrounds.

The field test data for the peak area checks are from a Hanford well (T50-01-06) with a data collection time of about 80 seconds, which is typical of field data collected at Hanford. The radionuclide contaminant chosen for testing the peak area calculation is $60 \mathrm{Co}$ in a low, but still measurable, concentration. As shown in Table 3.3.1, the values for net counts and count rates agree well among the compared methods. Specifically, the peak area count rates for all five methods are within the calculated statistical uncertainty of each other. The hand calculation used the same peak limits as selected by the LGCALC analysis program ("Program"), based on a personal judgement of suitable peak boundaries. The calculated gross counts and background were different for the two Ortec programs, which selected wider peak limits. The log analysis program and the hand calculation converted the count rates to concentrations of ${ }^{60} \mathrm{Co}$ using the detector efficiencies and casing corrections given previously in Table 3.2.1. The statistical uncertainties in the resulting concentrations include uncertainties propagated from count rates, efficiency, and casing factors. Slightly different uncertainties are obtained from the two methods because the hand calculation uses the more rigorously correct analysis recommended in Section 4.1.1. The concentrations of $60 \mathrm{Co}$ calculated separately from its two gamma-ray peaks at 1173 and $1333 \mathrm{keV}$ are $2.85 \pm 0.35$ and $3.72 \pm 0.40 \mathrm{pCi} / \mathrm{g}$, respectively. The log analysis program selects for reporting only the concentration having the lowest percent uncertainty. As discussed in later in Section 4.1.1, it would probably be better to report a weighted average of the concentrations from the two 60 Co gamma rays. 
Table 3.3.1. Peak Area Calculations Using Field Data - $60 \mathrm{Co}$

\begin{tabular}{|c|c|c|c|c|c|}
\hline Item & Program & Hand Calc. & Omnigam & GammaVision & RayGun \\
\hline \multicolumn{6}{|l|}{ 1173-keV Peak } \\
\hline $\begin{array}{l}\text { Peak limits }(\mathrm{ch}) \\
\text { Gross counts } \\
\text { Background } \\
\text { Net counts } \\
\text { Net counts/second } \\
\text { Calc Conc (pCi/g) }\end{array}$ & $\begin{array}{l}1671-1675 \\
135 \\
13 \\
122 \\
1.56 \pm 0.16 \\
2.85 \pm 0.35(\mathrm{a})\end{array}$ & $\begin{array}{l}1671-1675 \\
135 \\
13 \\
122 \\
1.56 \pm 0.15 \\
2.85 \pm 0.35\end{array}$ & $\begin{array}{l}1669-1679 \\
154 \\
28 \\
126 \\
1.62 \pm 0.18 \\
-\cdots--\end{array}$ & $\begin{array}{l}1666-1680 \\
168 \\
49 \\
119 \\
1.53 \pm 0.17 \\
\cdots \cdots\end{array}$ & $\begin{array}{l}1670-1676 \\
145 \\
19 \\
126 \\
1.62 \pm 0.17 \\
\cdots \cdots\end{array}$ \\
\hline \multicolumn{6}{|l|}{ 1333-keV Peak } \\
\hline $\begin{array}{l}\text { Peak limits (ch) } \\
\text { Gross counts } \\
\text { Background } \\
\text { Net counts } \\
\text { Net counts/second } \\
\text { Calc Conc (pCi/g) }\end{array}$ & $\begin{array}{l}1896-1904 \\
162 \\
5.4 \\
157 \\
2.01 \pm 0.17 \\
3.72 \pm 0.40(a)\end{array}$ & $\begin{array}{l}1896-1904 \\
162 \\
5.4 \\
157 \\
2.01 \pm 0.16 \\
3.72 \pm 0.42\end{array}$ & $\begin{array}{l}1895-1904 \\
163 \\
27 \\
136 \\
1.75 \pm 0.19 \\
-\cdots\end{array}$ & $\begin{array}{l}1894-1904 \\
166 \\
4 \\
162 \\
2.08 \pm 0.15 \\
-\cdots\end{array}$ & $\begin{array}{l}1896-1904 \\
162 \\
9 \\
153 \\
1.97 \pm 0.17 \\
\cdots-\end{array}$ \\
\hline
\end{tabular}

(a) $\log$ does not routinely report statistical uncertainty; value obtained from special printout; see 4.1 .1 below. Well T50-01-06, sample depth $=55.0 \mathrm{ft}$; counting live time $=77.86$ seconds; uncertainties are $1 \mathrm{std}$. dev .

Table 3.3.2 shows comparisons of peak areas for $\mathrm{K}, \mathrm{U}$, and Th obtained using data collected in the "mixed zone" of the Hanford calibration models. The collection time for these data is about 1000 seconds, which provides much better counting statistics than do the relatively short periods during field logging. The good counting statistics of this set of data allow a comparison of the five methods of obtaining peak areas under conditions of well-defined, high-count peaks. Again, the net count rates are in good agreement for the various methods, in each case being within the calculated statistical uncertainty of each other.

The agreement in peak areas calculated by the five methods indicates that the log analysis program is performing correctly in determining the peak area count rates from which subsurface radionuclide concentrations are calculated. More exhaustive tests might show applications in which the program fails to find a peak or determines the wrong count rate for it. However, these tests did not appear to be warranted based on these results and WHC's past experience of using the program. Peaks that are closely spaced in a spectrum can create analysis difficulties in separating the peaks and determining appropriate backgrounds. However, for applications where the list of potential radionuclide contaminants is known and limited, such as near Hanford waste tanks, logging should not reveal any "surprise" peaks, and closely-spaced peaks should not be a problem. More elaborate peak-finding and peak-fitting programs exist that could be used in the future if problems are encountered in practical experience. 
Table 3.3.2. Peak Area Calculations Using Hanford Calibration Model Data (Mixed Zone)

\begin{tabular}{|c|c|c|c|c|c|}
\hline Item & Program & Hand Calc. & Omnigam & GammaVision & RayGun \\
\hline \multicolumn{6}{|l|}{ 1461-keV Peak_(K) } \\
\hline $\begin{array}{l}\text { Peak limits (ch) } \\
\text { Gross counts } \\
\text { Background } \\
\text { Net counts } \\
\text { Net counts/second }\end{array}$ & $\begin{array}{l}2091-2099 \\
5428 \\
2027 \\
3401 \\
4.32 \pm 0.10\end{array}$ & $\begin{array}{l}2091-2099 \\
5428 \\
2027 \\
3401 \\
4.32 \pm 0.10\end{array}$ & $\begin{array}{l}2088-2103 \\
7017 \\
3592 \\
3425 \\
4.35 \pm 0.17\end{array}$ & $\begin{array}{l}2089-2103 \\
6774 \\
3399 \\
3375 \\
4.29 \pm 0.12\end{array}$ & $\begin{array}{l}2090-2100 \\
5917 \\
2571 \\
3346 \\
4.25 \pm 0.12\end{array}$ \\
\hline \multicolumn{6}{|l|}{ 1764-keV Peak (U) } \\
\hline $\begin{array}{l}\text { Peak limits (ch) } \\
\text { Gross counts } \\
\text { Background } \\
\text { Net counts } \\
\text { Net counts/second }\end{array}$ & $\begin{array}{l}2526-2537 \\
14102 \\
1150 \\
12947 \\
16.45 \pm 0.15\end{array}$ & $\begin{array}{l}2526-2537 \\
14102 \\
1150 \\
12947 \\
16.45 \pm 0.15\end{array}$ & $\begin{array}{l}2523-2541 \\
14807 \\
2016 \\
12791 \\
16.25 \pm 0.20\end{array}$ & $\begin{array}{l}2524-2540 \\
14612 \\
1821 \\
12791 \\
16.25 \pm 0.16\end{array}$ & $\begin{array}{l}2526-2537 \\
14102 \\
1199 \\
12903 \\
16.39 \pm 0.16\end{array}$ \\
\hline \multicolumn{6}{|c|}{ 2615-keV Peak (Th) } \\
\hline $\begin{array}{l}\text { Peak limits (ch) } \\
\text { Gross counts } \\
\text { Background } \\
\text { Net counts } \\
\text { Net counts/second }\end{array}$ & $\begin{array}{l}3743-3757 \\
7708 \\
127 \\
7581 \\
9.63 \pm 0.12\end{array}$ & $\begin{array}{l}3743-3757 \\
7708 \\
127 \\
7581 \\
9.63 \pm 0.11\end{array}$ & $\begin{array}{l}3739-3762 \\
7791 \\
206 \\
7585 \\
9.63 \pm 0.12\end{array}$ & $\begin{array}{l}3741-3759 \\
7747 \\
238 \\
7509 \\
9.54 \pm 0.11\end{array}$ & $\begin{array}{l}3742-3757 \\
7724 \\
156 \\
7568 \\
9.61 \pm 0.12\end{array}$ \\
\hline
\end{tabular}

counting live time $=787.22$ seconds; uncertainties are one std. dev.

\subsection{Recommended Changes}

Examining the analysis software has shown some possible changes that could improve the code. The changes involve algorithm modifications for some of the code's calculations (e.g., statistical uncertainty) and comment line changes to reflect the present status of the code and provide additional guidance for future maintainers of the code. Modifications are also needed to handle multiple detectors and logging tools with their individual calibration factors. The recommended changes are divided into "near term" and "far term" in the following sections. The near-term changes are not extensive and will require only moderate resources to implement. The resulting analysis code will be suitable for immediate use in analyzing germanium-detector data acquired by the new logging trucks once the calibrations of the new logging tools have been determined. The far-term recommendations involve more extensive changes that could further improve the data analysis, but would likely require extensive time and funding to implement.

\subsection{Near Term}

\subsubsection{Statistical Uncertainties and Weighted Averaging}

Correct calculation and propagation of statistical uncertainties (Beers 1953; Stromswold and Kosanke 1978) is important because it provides information on the accuracy of the calculated radionuclide concentrations. These uncertainties arise from the statistical nature of gamma-ray 
emission and from uncertainties inherent in detector calibration and correction factors, such as those for steel casing and borehole water.

The analysis program calculates statistical uncertainties and propagates them through the various data processing steps, starting with the uncertainty in peak area and ending with the uncertainty in calculated concentration. Although the program calculates these uncertainties, they are not presented in the normal data analysis output. Some changes in the algorithms used to calculate the uncertainties in subroutines NUCEFF and PKCNT should be made to make the uncertainty calculations more rigorously correct. See Appendix A for recommended code line changes. In addition, there should be a change in the method of determining the concentration of radionuclides that emit multiple gamma rays during their decay process. The program calculates separate concentrations and uncertainties for each of the multiple gamma rays. The subroutine NUCAMT should determine a final radionuclide concentration based on the weighted average of the separate concentrations, whereas the original program reports the single concentration that has the lowest percent uncertainty. By including the information from multiple gamma rays, weighted inversely with the square of their uncertainty, improved statistical results should be obtained. A provision for excluding contributions from peaks that have very poor uncertaintios can prevent undesirable effects on the average values.

\subsubsection{Branching Ratios for $234 \mathrm{mPa}$}

Calculating the concentration of gamma-ray-emitting radionuclides requires knowledge of the number of gamma rays emitted during the decay process. Published values for these branching ratios are used in subroutine NUCEFF. The branching ratios used in calculating $238 \mathrm{U}$ from its second daughter $234 \mathrm{mPa}$ should be updated to the values reported by Moss (1986). The new values should be 0.832 (gammas per 100 decays) for $1001 \mathrm{keV}$ and 0.314 for $767 \mathrm{keV}$.

\subsubsection{Casing Correction}

The casing corrections should be extended to steel casings that are up to about 1.0 inches thick to cover the range of casings present at Hanford. The present casing corrections stop at a thickness of 0.40 inches. As a result, when thicker casings are now logged, the predicted concentrations are corrected only to 0.40 -inch casing, resulting in a calculated concentration that is too low.

For casing thicknesses not available during calibration, the program interpolates between two measured thicknesses, assuming a linear dependence. The theory of gamma-ray attenuation indicates that attenuation is an exponential function. Hence the interpolation method could be changed to an exponential one, done piecewise between two known values. Comparing results using linear and exponential interpolation, based on data presented in Koizumi et al. (1992) and Koizumi (1993), gave inconclusive experimental evidence of which method is better. In practical terms, it probably does not matter much which method is used, but switching to exponential interpolation will match the theory better.

\subsubsection{Handling Multiple Detectors and Logging Tools}

Adding new logging tools with different size detectors and different thicknesses of tool housings will necessitate special provisions to ensure that spectral data are processed with the appropriate calibration and correction factors for each tool. In the present version of the program, the calibration and correction factors are coded directly into the program with no provision for multiple detectors or logging tools. The analysis program should be modified to input a tool identification, such as a serial number, which will enable the correct detector efficiency and correction factors to be used during processing. 


\subsubsection{Comment Lines}

Most of the program is very well documented with comments. In a few places, however, the comments have not kept up with other program changes. These comments should be updated so that they accurately describe the present program. See Appendix A for the needed changes in comments.

\subsection{Far Term}

Possible far-term changes in the code include alternative methods for determining peak areas, enhanced processing to deconvolve thin zones of contaminants, and making the program easier to operate.

\subsubsection{Peak Identification and Area Calculation}

The present program locates peaks by looking for statistically significant increases in counts as it steps through a spectrum. The background under a peak is determined from the counts in the ten channels preceding and following a peak. Alternative methods for finding and quantifying peaks are possible. Commercial programs exist that analyze conventional, laboratory-acquired spectra from germanium detectors. Some of these programs fit pre-determined mathematical shapes to the peaks in determining peak areas. In addition, they can measure peak width \{e.g., full width at half maximum( FWHM) $\}$ as an indicator of detector performance, and they can deconvolve multiple, closely spaced peaks. The applicability of these more elaborate fitting programs could be evaluated for logging data where counts in the peaks can be low and the peaks can be poorly defined. These tests were not performed during the present code evaluation, partly due to time and funding constraints, and partly. due to the author's opinion that the limitations inherent in logging data do not warrant elaborate peak-fitting procedures. However, a relatively simple method, suggested by $\mathrm{C}$. J. Koizumi, could be evaluated for identifying the presence of muitiple, closely spaced peaks. This method uses the ratio of a peak's full width at tenth maximum (FWTM) to FWHM to set a warning flag if a "wide" peak if found, possibly indicating multiple, closely spaced peaks.

\subsubsection{Vertical Deconvolution for Thin Zones}

The present data analysis is based on uniform radionuclide distributions within the region of spatial sensitivity of the detector. Special processing can, in principle, improve the vertical response of the logging system to changes in radionuclide concentration along the axis of the borehole (Conaway and Killeen 1978; Wilson et al. 1979; Jacobson 1989; Gadeken et al. 1990). John Conaway, Los Alamos National Laboratory, will deliver a computer program to Hanford in late 1994 for processing radionuclide concentrations obtained from LGCALC to obtain an improved definition of thin zones. In implementing this thin-bed deconvolution, care will be needed to ensure that the statistical uncertainty of the final concentrations is not degraded to an unacceptable amount. Future improvements should also determine the optimum data-collection intervals along the length of the borehole for best identification of thin zones. Conaway's results will provide guidance on this.

\subsubsection{Ease of Operation}

The code requires extensive operator training and experience in spectroscopy to obtain correct and complete analysis of data. Operator involvement is needed at several stages during the analysis process that begins with retrieval of logging data and ends with generating well logs and tables of radionuclide concentrations. For example, the person running the program must ensure that the energy calibration is correct so that the code can properly correlate peaks with specific radionuclides. Additional operator input can be required to resolve peak identification problems in the case of gain shifts or poorly defined peaks due to low counts. Fully automating the analysis process will never be practical due to the need for a trained analyst to resolve inevitable problems in analyzing complex gamma-ray spectra. However, implementing the code at WHC Tank Waste 
Remediation Systems will likely identify possible areas for improvement. These improvements in operational analysis can be made at a later time.

\subsection{Conclusion}

The logging data analysis program LGCALC has been examined and found suitable for processing data to be collected by new high-resolution gamma-ray logging trucks scheduled to begin operational tests within WHC Tank Waste Remediation Systems. Most of the code requires no changes, but in a few limited cases, suggestions have been made to correct errors or improve operation.

The technical review has confirmed the appropriateness, correctness, completeness, and coding accuracy of algorithms used to process spectral gamma-ray data, leading to a calculation of subsurface radionuclide contaminants. Running the program with test data from calibration models and Hanford boreholes has confirmed that the program operates correctly. Comparisons with "hand calculations" and commercial peak-analysis programs have shown the correctness of the output from the program

The recommended action based on this review of the code is to make the "near term" programming changes suggested in Section 4.1 and then use the LGCALC program with the new high-resolution logging systems once they have been properly calibrated.

\subsection{References}

Beers Y. 1953. Introduction to the Theory of Error, Addison-Wesley, Cambridge.

Conaway J. G. and P. G. Killeen. 1978. "Quantitative Uranium Determinations from Gamma-Ray Logs by Application of Digital Time Series Analysis." Geophys., 43, No. 6, 1204-1221.

Engelman R. E., D. C. Stromswold, and W. H. Ulbricht. 1993. Alternatives Evaluation for Spectral Gamma-Ray Data Analysis Software. Westinghouse Hanford Company publication WHC-SD-WMTA-149, Richland, Washington.

Gadeken L. L., G. A. Merchant , L. A. Jacobson , and C. C. Fu. 1990. "The Utility of Combining Smoothing and Deconvolution in Processing Algorithms for Well Log Data." Conf. Record of 1990 IEEE Nuc. Sci. Symp., 810-816.

Hearst, J. R., J. R. Brodeur, C. J. Koizumi, J. G. Conaway, J. L. Mikesell, P. H. Nelson, D. C Stromswold, and R. D. Wilson. 1993. DOE Capabilities for In-Situ Characterization and Monitoring of Formation Properties in the Vadose Zone. Presented at ER'93 Environmental Remediation Conference, Augusta, GA, Oct. 24-28. Lawrence Livermore National Lab. report UCRL-JC-113790, Livermore, California.

Jacobson, L. A. 1989. "A Matched Filter Data Smoothing Algorithm." IEEE Trans Nuc. Sci., Vol. 36, No. 1, 1227-1231.

Koizumi C. J., R. K. Price, and R. D.Wilson. 1992. Calibration of the RLS HPGE System for 200 Area Management Study Screening Measurements. Westinghouse Hanford Company publication WHC-SD-EN-TRP-001, Richland, Washington. 
Koizumi, C. J. 1993. Calibration of the Radionuclide Logging System Germanium Detector.

Westinghouse Hanford Company publication WHC-SD-EN-TRP-004, Rev. 0, Richland, Washington.

Moss C. E. 1986. "Gamma-Ray Line Intensities for Depleted Uranium." Radiat. Eff. 94, 81-84.

Steele, W. D. and D. C. George. 1986. Field Catibration Facilities for Environmental Measurements of Radium, Thorium, and Potassium. Bendix Field Eng. Corp. report GJ/TMC-01 (2nd ed.), Grand Junction, Colorado.

Stromswold D. C. and K. L.Kosanke. 1978. "Calibration and Error Analysis for Spectral Radiation Detectors." IEEE Trans.Nuc. Sci., Vol. 25, No. 1, 782-786.

Wilson R. D., D. C. Stromswold, M. L.Evans, M. Jain, and D. A. Close. 1979. "Spectral Gamma-Ray logging III: Thin Bed and Formation Effects." Trans. of Society of Professional Well Log Analysts Annual Logging Symp., paper FF, Houston, Texas. 
Appendix A

Program Questions Addressed During Evaluation and Recommended Code Changes 


\section{Appendix A}

\section{Program Questions Addressed During Evaluation and Recommended Code Changes}

During the review of the LGCALC program, some questions arose about the Fortran code. This appendix describes those questions and their answers. Also, recommended code changes are given here for some of the program's routines. These changes concern mainly improvements to the algorithms that calculate statistical uncertainty. Finally, some recommended changes to comment lines within the code are presented.

\section{LGCALC}

Comments describing Steps 1-3 at the beginning of the program are not quite correct for the current program version; there are 5 steps now.

\section{Step 1}

What are CMOV and CFOLD? Answer: CMOV is used to move a character strin'g in MBUF to a more convenient place called MLINE. CFOLD is then used to "standarcize" the string by converting it to upper case. This makes testing the string easier. -- C. A. Oster (CAO), IR.M

Step 2

The comment's description of this step seems incorrect for the present program version. Perhaps a better description would be "Prepare for spectra processing."

When spectra files are brought in for processing, do data come for one depth only or do they come as a file containing many depths, perhaps for the whole well? Answer: One depth only.

MLINE $=$ MWELL

MLINE(16:57) $=$ ' ' What is being done here? Answer: MLINE is a CHARACTER*80 variable. The right member of this statement contains 41 characters. Characters 16 through 56 of MLINE are replaced by the 41 characters of the right member. Character 57 is replaced by a blank. This last item is immaterial for this statement as the next statement MLINE(57:78) $=\ldots$ replaces characters 57 through 77 with the 21 characters in the right member. Character 78 is replaced by a blank. I suspect that because MWELL (refer to the statement before the two discussed above) is a CHARACTER*16 variable that the two statements should be altered to read

$\operatorname{MLINE}(17: 57)=\ldots$

$\operatorname{MLINE}(58: 78)=\ldots$

This should probably be tested before it becomes final. -- CAO

Step 3

Call NCF(MDEPST,16,DEPST): What are MDEPST and DEPST variables? Answer: They are character and floating point versions of the same depth variable. Correction factors for casing and water are updated when the depth gets beyond the top (XTOP) and bottom (XTBOT) limits of the present interval in the well where casing and water values are already set.

XLVTIM = JLVTIM/50. Why divide by 50 in calculating live time? Answer: The EG\&G Ortec data-collection system in the logging truck stores time in units of $20 \mathrm{~ms}$. Dividing by 50 converts the time back to seconds. 


\section{CASING}

Step 1

$\operatorname{IMAX}=\mathrm{NPARM} / 4$

IMAX $=4$

Why calculate IMAX and then set it to 4? What is NPARM? In the revised program, perhaps set

IMAX to 4 rather than calculating it from NPARM, which is set to value 20 in LGCALC.

Where are subroutines FVAL and SPOSN? Answer: FVAL and SPOSN are contained in the Data Analysis System (DAS). These routines are used to access the capabilities of the IBM-PC computer system. FVAL gets floating point values from analyst's screen parameters. SPOSN positions the cursor on the screen. -- CAO

Do CASDI and CASID both refer to the inside diameter of the casing, as opposed to the outside diameter? Answer: Yes

Step 3

DO $150 \mathrm{I}=1, \mathrm{ICNT}$

IF ......THEN

ENDIF

IF(CASTHK(I) .LE. AIRH2O) AIRH2O = CASID(I)

150 CONTINUE

It is perhaps better to look for the smallest diameter casing directly by making the line to be IF(CASID(I).LE.AIRH2O) AIRH2O = CASID(I).

\section{NUCFIL}

Step 1

Perhaps a better description of this step would be "Check to see if the output file has already been opened; if not, open it."

\section{Step 2}

Perhaps a better description of this step would be "Output headings to Mono.pks,"

i.e., avoid any mention of concentrations, which are not written in this subroutine.

Why is the file called "mono.pks" even when multi-gamma peaks are written to it? Answer: The results for multi-gamma peaks go into this file after the program has selected the single peak that has the lowest percent uncertainty in the calculated concentration for that radionuclide. Putting these results in the mono.pks file places the results for the complete set of radionuclides into one file.

\section{NUCLID}

\section{READ DISK FILE OF NUCLIDES AND INTENSITIES}

What file is being read? Answer: The input file is NUCLIDES.FIL. The code locks in several places for this file. Once it is located, processing continues. -- CAO. The file NUCLIDES.FIL is set up by the analyst at the start of processing. It contains the list of radionuclides (with the ir gamma-ray energies and branching ratios) that are to be analyzed in running LGCALC.

Has the spectrum been analyzed already? Answer: No. -- CAO

In comments, replace "INTENSITIES" by "BRANCHING RATIOS." The term "intensity" could be misunderstood as the measured intensity (peak area) obtained during logging.

Delete "half-life" from the comment that describes how the concentration is calculated. Half-life does not enter the calculation when working only with $\mathrm{Ci} / \mathrm{g}$. 
Step 1

Above line 91, what does *91 mean? How do you get to lines 91, 92, 93 ? Answer: The *91 is a non-standard return argument. This device is sometimes used when something within the subroutine happens that requires special action after returning to the calling program. Typically, it is used for error returns, but it can be used for other things as well. The call statement is read as follows: If the return is standard, resume computation at the next statement. If the return is nonstandard (in this case, through the $* 91$ ) resume computation at statement 91 . This also answers the question of how does the program get to statements 91,92 and 93 . -- CAO

Step 2

CALL NCF (MVAL, LPARM, XGAMMA) Does this convert to floating point, as the preceding comment indicates? Answer: Yes --CAO

Step 8

KEVLO $=0 \quad$ This variable is never used.

\section{NUCEFF}

Add comments to identify the date of the calibration and correction factors included in this subroutine (e.g., "Detector efficiency, water, casing, and lead shield factors obtained using 1992 calibration data.").

Add a comment to identify the particular logging tool (e.g., model/serial number) to which the calibration and corrections apply.

Note: Once additional logging tools and detector sizes become available, the program will need to be able to select and apply the correct calibration and correction information for each tool.

\section{F1,F2 = EQUATION CONSTANTS (SEE CS375)}

The "SEE CS375" is confusing. Perhaps omit this and the comment "C CS375, CSE375 ..." which appears to be left over from an earlier version of the program.

Revise the comment about CF to delete the words "HALF LIFE." The conversion factor does not depend on half life when concentrations are calculated in terms of $\mathrm{pCi} / \mathrm{g}$.

Step 1

Add a comment to explain that $\mathrm{H} 1 \mathrm{E}, \mathrm{H} 2 \mathrm{E}$, and $\mathrm{H} 3 \mathrm{E}$ are one-standard-deviation errors (uncertainties) associated with $\mathrm{H} 1, \mathrm{H} 2$, and $\mathrm{H} 3$.

H1, H2...H3E do not quite match the values in the Koizumi et al. (1992) or Koizumi (1993) calibration reports. Cite the source for these values.

Is the $10^{-2}$ factor missing from the detector efficiency constants properly accounted for elsewhere so that the correct concentration is calculated? Answer: The branching ratios stored in NUCLIDES.FIL contain the compensating factor to make the calculation correct.

W1...W2E: These values were not given in the Koizumi et al. (1992) calibration report. Cite the source of these values. Check the correctness of the values. Answer: The values are given in the Koizumi (1993) calibration report.

The maxinum water-filled hole diameter for which a correction is made is 12 inches. Do we ever encounter any larger, water-filled holes? If so, we need to extend the correction. Answer: Hanford holes are adequately covered by the existing calibration range.

The maximum casing thickness handled in the present casing correction is 0.40 inches. This should extend to thicker casings, which can be encountered in multiple casing strings. Recent calibration 
data can extend the casing thickness correction to about 1 inch, which is adequate for Hanford wells.

CA ....CCE: The lead shield factors are not given in the Koizumi et al. (1992) calibration report. Where did these values come from? Answer: They are in the Koizumi (1993) calibration report.

Step 2

The error calculation for water correction needs modification:

delete: $\mathrm{EEE}=\mathrm{SQRT}\left(\mathrm{W} 1 \mathrm{E}^{*} \mathrm{~W} 1 \mathrm{E}+(\mathrm{W} 2 \mathrm{E} / \mathrm{E})^{* * 2}\right)$

add: $\quad \mathrm{EEE} 1=((1-\mathrm{WFACT}) * * 2) *(\mathrm{~W} 1 \mathrm{E} * \mathrm{~W} 1 \mathrm{E}+$

$(\mathrm{W} 2 \mathrm{E} / \mathrm{E}) * * 2) /(4 *(\mathrm{~W} 1+\mathrm{W} 2 / \mathrm{E}))$

$\mathrm{EEE} 2=(\mathrm{WFACT} * * 2) *(\mathrm{WAE} * \mathrm{WAE}+(\mathrm{WBE} / \mathrm{E}) * * 2) /(4 *(\mathrm{WA}+\mathrm{WB} / \mathrm{E}))$

$\mathrm{EEE}=\mathrm{SQRT}(\mathrm{EEE} 1+\mathrm{EEE} 2)$

C INITIALIZE LEAD SHIELD CORRECTION FACTOR

Move the initializing equations $(\mathrm{CL}=1.0$ and $\mathrm{CLE}=0.0$ ) to just after this comment to achieve symmetry with other correction initializations and to make the comment correct. The initializing equations are now in Step 1 after line 103.

The error calculation for lead-shield correction needs modification: delete: $\mathrm{CLE}=\mathrm{CL} * 0.80$

add: $\mathrm{CLE}=\mathrm{SQRT}\left(\mathrm{CAE} * \mathrm{CAE}+\mathrm{CBE}^{*} \mathrm{CBE}^{*}(\mathrm{EXP}(-\mathrm{E} / \mathrm{CC}))^{* * 2}\right.$

$\left.+\mathrm{CCE}^{*} \mathrm{CCE}^{*}(\mathrm{EXP}(-\mathrm{E} / \mathrm{CC}))^{*} \mathrm{CB} *(\mathrm{E} / \mathrm{CC})^{* * 2}\right)$

The error calculation for casing correction needs modification:

delete: $\mathrm{EEE}=\mathrm{SQRT}(\mathrm{E} 1 * \mathrm{E} 1+(\mathrm{E} 2 / \mathrm{XLN}) * * 2)$

delete: $\mathrm{UNC}=\mathrm{CS}^{*} \mathrm{EEE}$

add:

$$
\begin{aligned}
& \mathrm{EE} 1=(((\mathrm{CFACT}-1) /(\mathrm{F} 1+\mathrm{F} 2 / \mathrm{XLN}) * * 2) * * 2) * \mathrm{E} 1 * \mathrm{E} 1 \\
& \left.\mathrm{EE} 2=(((\mathrm{CFACT}-1) / \mathrm{XLN}) /(\mathrm{F} 1+\mathrm{F} 2 / \mathrm{XLN}) * * 2)^{* * 2}\right) * \mathrm{E} 2 * \mathrm{E} 2 \\
& \mathrm{EEA}=\left((\mathrm{CFACT} /(\mathrm{FA}+\mathrm{FB} / \mathrm{XLN}) * * 2)^{* * 2}\right) * \mathrm{EA} \mathrm{EA} \\
& \mathrm{EEB}=(((\mathrm{CFACT} / \mathrm{XLN}) /(\mathrm{FA}+\mathrm{FB} / \mathrm{XIN}) * * 2) * * 2) * \mathrm{~EB} * \mathrm{~EB} \\
& \mathrm{UNC}=\mathrm{SQRT}(\mathrm{EE} 1+\mathrm{EE} 2+\mathrm{EEA}+\mathrm{EEB})
\end{aligned}
$$

$\mathrm{CF}=\mathrm{XINV} * 27 . / \mathrm{XN}$ Confirm that $\mathrm{XN}$ (which is GAMMAS(I,J)) is in units of gammas per 100 decays (rather than gammas per decay) to properly account for the missing $10^{-2}$ factor in XINV. Answer: The XN, which ultimately comes from the branching ratios stored in the file NUCLIDES.FIL, contains the needed factor to make the calculation correct.

\section{LGCALB}

Steps $2 \& 3$

ICHLOW $=(($ ILOW-XCALB $) / X C A L M X)+1 . U$

$\mathrm{ICHHI}=((\mathrm{IHI}-\mathrm{XCALB}) / \mathrm{XCALMX})+1.0$

IGOOD $($ IPTR $)=($ IKEV $($ IPPTR $)-X C A L B) / X C A L M X+1.0$

CH1 = ICHMAX-1

$\mathrm{CHX}=\mathrm{ICHMAX}-1$

Why add 1 when going from floating point to integer and subtract 1 when going from integer to floating point? Better to add 0.5 to round off the floating point to an integer, etc? Answer: One reason could be that both ICHLOW and ICHHI are used as limits in the DO 110 loop. -- CAO

Step 3

What is the reason for not calculating a new y intercept when a new slope is calculated when two calibration points are available? Answer: Experience has shown that gain drifts in the equipment are best tracked by changing the slope. -- R. K. Price 


\section{PKCNT}

INTEGER*4 JRLTIM, JLVTIM, JMCA(8200) Why is time an integer? What are units of time? Answer: The Ortec system that collects the data stores tirse in units of $20 \mathrm{~ms}$.

Step 1

JLIMIT $=\mathrm{X}+(\mathrm{SQRT}(\mathrm{X}) * 3$

A better equation is JLIMIT $=\mathrm{X}+((\mathrm{SQRT}(\mathrm{JSUM}) / \mathrm{IWIDE}) * 3$. Don't take the square root of the number of channels.

Step 7

Omit the comments on the detailed version of the uncertainty calculation. They suggest it is OK to divide counts by channels before taking square roots for uncertainty calculations.

XLVTIM = ILVTIM / 50. Why divide by 50? What are time units for JLVTIM? Answer: Units are $20 \mathrm{~ms}$. Dividing by 50 converts to seconds.

Revise the uncertainty calculation (to account for high- and low-side backgrounds as independent variables):

delete: UNCCPS $=$ SQRT(JSUM + TOTBKG) $/$ XLVTIM

add: UNCCPS $=$ SQRT (JSUM + TOTBKG*CHNUM $/(2 *$ IWIDE $)) /$ XLVTIM

delete: $X=$ SQRT(AVGBKG)

add: $\quad X=S Q R T(F L O A T(J B 1+J B 2)) /(2 *$ IWIDE $)$

\section{PKSORT}

No questions or suggested changes.

\section{NUCAMT}

Omit the comment: C COMMON/CGAMMA.

Add the word "Percent" in comment: C --NUCLIDE CONCENTRATION REPORTED IS MINIMUM PERCENT UNCERTAINTY. Note: this comment will need to change if the reported uncertainty becomes the weighted average uncertainty, as described below.

It would perhaps be better to report a weighted average of the concentrations calculated from multiple gamma rays. The code lines for calculating the concentration that is weighted inversely with uncertainty are as follows:

DENOM $=0.0$

DO $120 \mathrm{I}=1, \mathrm{NPEAKS}(\mathrm{J})$

CPS $=$ CPSPK(I,J)

CALL NUCALC (I,J,CONC,CERR)

HOLD $(\mathrm{I})=\mathrm{CONC}$

HOLDER(I) = CERR

C PREPARE FOR WEIGHTED AVERAGING OF CONCENTRATION FOR PEAK J

IF (CONC .GT. 0.0.AND.CERR.GT.0.0.AND.CERR.LT.ERRMAX) THEN

$\operatorname{CONCEN}(\mathrm{J})=\mathrm{CONCEN}(\mathrm{J})+\mathrm{CONC} /(\mathrm{CERR} * * 2)$

DENOM $=$ DENOM + 1.0/(CERR $* * 2)$

ENDIF

$\mathrm{PCT}=\mathrm{CERR} / \mathrm{CONC} * 100$

C -.- BUILD COMPUTED CONCENTRATION TO SEPARATE FILE. II $=-$ I 


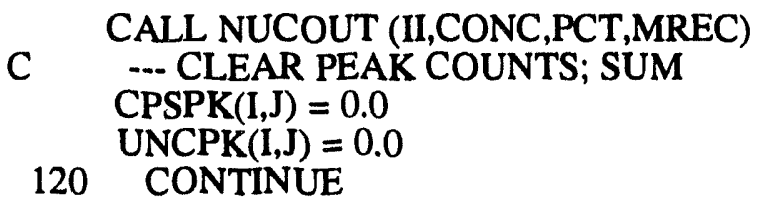

C CALCULATE WEIGHTED AVG CONCENTRATION AND ITS UNCERTAINTY $\operatorname{CONCEN}(\mathrm{J})=\operatorname{CONCEN}(\mathrm{J}) / \mathrm{DENOM}$

\section{NUCALC}

The calculation of the concentration and its uncertainty looks correct, but it could be done in fewer steps, in case taking the square roots introduces any error or excessive calculational time:

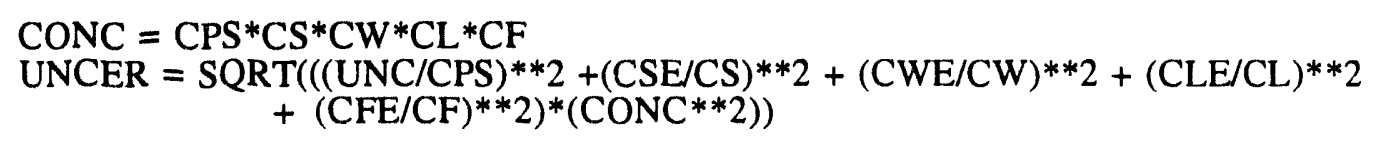

Additional comment by $\mathrm{C}$. A. Oster concerning the subroutine RCHNF: JMCA is dimensioned as 8200 . In the code, there is a test to ensure that INVMCH is $\leq 9200$ before reading into JMCA. This test should be changed to $\leq 8200$.

\section{References}

Koizumi C. J., R. K. Price, and R. D.Wilson. 1992. Calibration of the RLS HPGE System for 200 Area Management Study Screening Measurements. Westinghouse Hanford Company publication WHC-SD-EN-TRP-001, Richland, Washington.

Koizumi, C. J. 1993. Calibration of the Radionuclide Logging System Germanium Detector. Westinghouse Hanford Company publication WHC-SD-EN-TRP-004, Rev. 0, Richand, Washington. 


\section{Distribution}

No. of

Copies

\section{Offsite}

12
DOE/Office of Scientific and Technical Information

K. Klein

U.S. Department of Energy

Office of Energy Storage and

Distribution

Forrestal Bldg, CE-141

Washington, DC 20585
No. of

Copies

Onsite

DOE Richland Operations Office

C. H. Gunion, A5-20

19 Westinghouse Hanford Company

J. E.Andrews, S5-04

R. B.Bass, R1-01

P. J.Edwards, A1-04

J. A.Glasscock, R1-01

J. W.Fassett, H6-06

G. T.Frater (Tom), T4-01

W. J.Jones, B5-19

K. A. Lane, R1-01

L. L.Lockrem, S3-90

J. E.Meinser, H6-06

R. A.Meznarich, S3-90

G. J.Miskho, R2-50

W. F.Nicaisse, H6-06

C. A.Oster, L4-91

R. K.Price, H6-06

R. R.Randall, H6-06

D. L.Scott, S5-60

W. H.Ulbricht, S3-90

R. K.Welty, R1-80

19

Pacific Northwest Laboratory

M. Bliss, P8-08

R. E. Engelman, K6-96

D. E. Robertson, P9-01

D. C. Stromswold, P8-01 (10) Publishing Coordination Technical Report Files (5) 

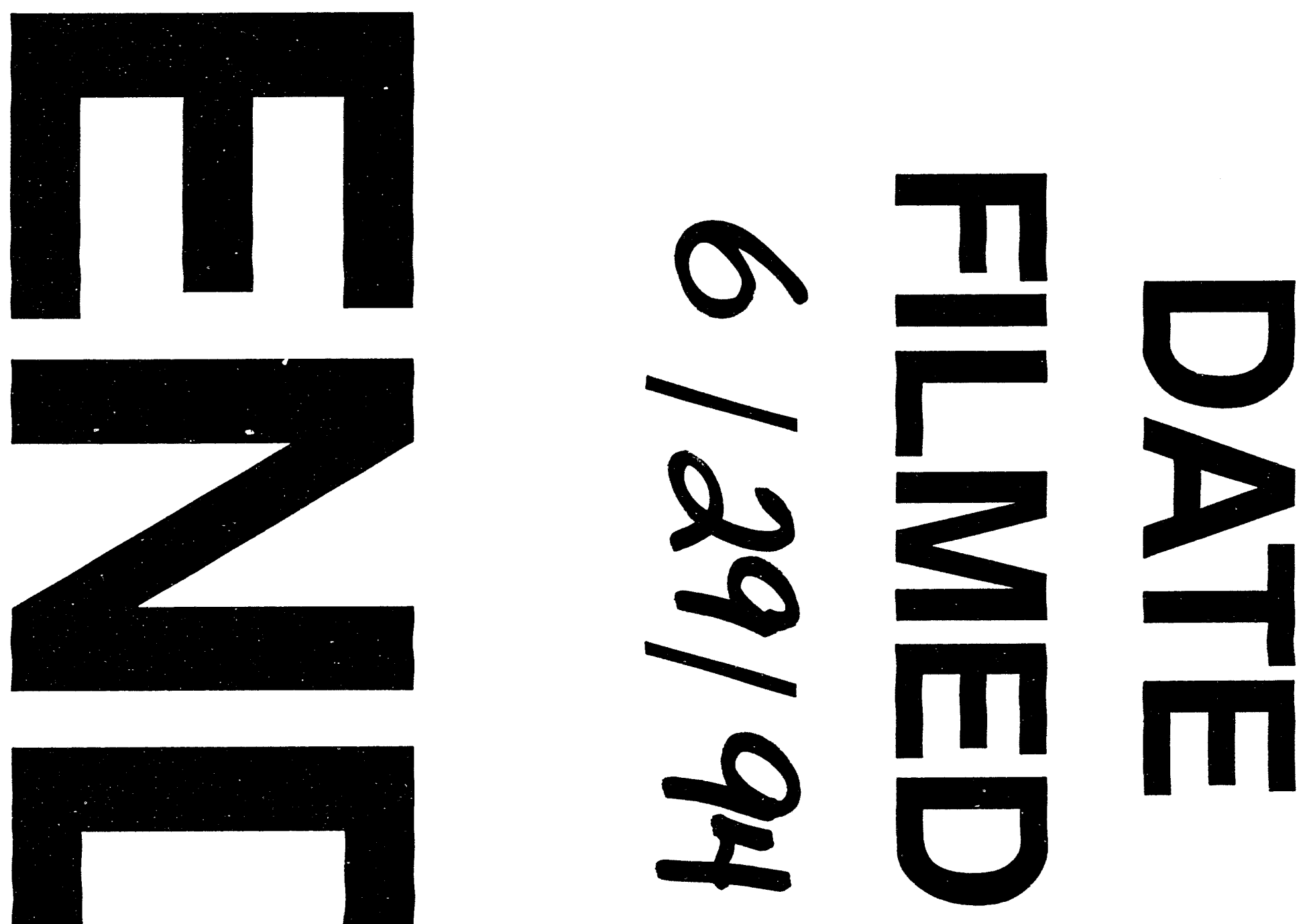